\title{
AVALIAÇÃO DA MICROSSÍLICA NA RESISTÊNCIA AO CHOQUE TÉRMICO DE ALUMINA COM 5\% DE ZIRCÔNIA*
}

\author{
Camila Valentina Ribeiro Portilho ${ }^{1}$ \\ Elton Douglas Heriger Pereira ${ }^{2}$ \\ Adrieli Oliveira da Silva ${ }^{3}$ \\ Thales Lima da Silva \\ Elias Fagury- Neto ${ }^{5}$ \\ Adriano Alves Rabelo ${ }^{7}$
}

\section{Resumo}

O processo siderúrgico necessita de tijolos refratários resistentes ao choque térmico em virtude das inúmeras solicitações térmicas, além de solicitações mecânicas e químicas. Refratários $\mathrm{C}$ exibem excelentes propriedades tecnológicas e boa resistência ao ataque de escórias, embora sua resistência ao choque térmico seja limitada, sendo utilizados em válvulas siderúrgicas. Este trabalho visa analisar refratários $\mathrm{Al}_{2} \mathrm{O}_{3}-\mathrm{ZrO}_{2} \mathrm{com}$ adições de microssílica, que pode melhorar eminentemente sua resistência ao choque térmico, pelo fato da microssílica apresentar uma eficácia no empacotamento da massa após mistura e ainda pela possível formação de mulita in situ através da reação com alumina. A possibilidade de formação de mulita in situ proporciona superior resistência à fluência e excelente resistência ao dano por choque térmico. Utilizou-se alumina, $5 \%$ de zircônia monoclínica e teores de 15, 25, 35 e 50\%.p de microssílica. Os corpos de prova foram prensados a 7 toneladas, sinterizados a $1600^{\circ} \mathrm{C} / 2 \mathrm{~h}$ e caracterizados quanto a resistência ao choque térmico, propriedades tecnológicas pelo método de Arquimedes, resistência à flexão á temperatura ambiente, análise microestrutural utilizando microscopia eletrônica de varredura e análise mineralógica através de difração de raios $\mathrm{x}$.

Palavras-chave: Mulita; Microssílica; Choque térmico.

\section{MICROSSILICA EVALUATION IN RESISTANCE TO ALUMINUM THERMAL SHOCK WITH 5\% OF ZIRCONIA}

\section{Abstract}

The steel process requires refractory bricks resistant to thermal shock due to the numerous thermal demands, as well as mechanical and chemical stresses. C refractories exhibit excellent technological properties and good resistance to slag attack, although their resistance to thermal shock is limited, being used in steel valves. This work aims to analyze Al2O3-ZrO2 refractories with microsilica additions, which can eminently improve their resistance to thermal shock, because the microsilica has an efficacy in the packaging of the mass after mixing and also for the possible formation of in situ mullite through the reaction with alumina. The possibility of in situ mullite formation provides superior creep resistance and excellent resistance to thermal shock damage. Alumina, 5\% monoclinic zirconia, and contents of 15, 25, 35 and 50\% .span of microsilica were used. The specimens were pressed at 7 tons, sintered at $1600^{\circ} \mathrm{C} / 2 \mathrm{~h}$ and characterized as resistance to thermal shock, technological properties by the Archimedes method, flexural strength at room temperature, microstructural analysis using scanning electron microscopy and mineralogical analysis Through diffraction of $x$ rays.

Keywords: Mulita; Microsilica; Thermal shock.

1 Engenharia de Materiais, graduanda, bolsista PIBic-FAPESPA, Instituo de Geociências e Engenharias, Unifesspa, Marabá, Pará, Brasil.

2 Engenharia de Materiais, graduando, bolsista PIBic-CNPq, Instituto de Geociências e Engenharias, Unifesspa, Marabá,Pará, Brasil. 
3 Engenharia de Materiais, graduanda, bolsista PIBic--CNPq, Instituto de Geociências e Engenharias, Unifesspa, Marabá, Pará Brasil.

4 Engenharia de Materiais, graduando, Aluno Voluntário de Iniciação Cientifica, Instituto de Geociências e Engenharias, Unifesspa, Marabá, Pará, Brasil.

5 Engenheiro Químico, Doutor, Pró Reitor de Ensino de Graduação, Instituo de Geociências e Engenharias, Unifesspa, Marabá, Pará, Brasil.

6 Engenheiro de Materiais, Doutor, Diretor Adjunto do Instituto de Geociências e Engenharias, Instituto de Geociências e Engenharias, Unifesspa, Marabá, Pará, Brasil.. 


\section{INTRODUÇÃO}

Entre os diversos segmentos industriais, a siderurgia tem sido o principal consumidor de refratários. Estudando-se a demanda de refratários por esse setor, verifica-se que as mudanças nos processos siderúrgicos influenciaram o perfil da demanda desses produtos. A tendência observada passou a ser para refratários de melhor qualidade, exigindo-se maior conteúdo tecnológico. Nesse contexto, o projeto da microestrutura tem um papel relevante. Material refratário é definido como sendo um material cerâmico, natural ou artificial, conformado ou não, geralmente não metálico, que retém a forma física e a identidade química quando submetido a altas temperaturas [1,2].

A alumina é um dos materiais cerâmicos mais utilizados como refratário estrutural para a siderurgia. Entre suas propriedades estão alta refratariedade, dureza, resistência ao ataque químico, alta resistência em altas e baixas temperaturas e rigidez dielétrica, módulo de elasticidade e condutividade térmica superior à maioria dos óxidos cerâmicos [1]. Contudo, algumas propriedades, tais como tenacidade à fratura baixa, microestruturas grosseiras e resistência à flexão baixa, limitam sua gama de aplicações estruturais, mas não chegam a ser problemas para aplicação como refratário. Assim, a alumina mantém-se na liderança da indústria de cerâmicas avançadas, devido ao seu custo moderado, sua versatilidade e comprovado desempenho. Como alternativa para as limitações do uso da alumina foi-se elaborada juntamente com a adição da microssílica, uma nova fase que conseguisse sanar essas limitações, que é a fase mulita.

Refratários do sistema $\mathrm{Al}_{2} \mathrm{O}_{3}-\mathrm{ZrO}_{2}$ apresentam excelentes propriedades, a $\mathrm{ZrO}_{2}$ quando adicionada melhora eminentemente as propriedades citadas acima, principalmente no que tange a tenacidade a fratura. Embora esse refratário apresente excelentes propriedades tecnológicas quando comparados aos de alumina, esses sofrem certas limitações devido apresentarem uma baixa resistência ao choque térmico. No entanto, sabe-se que a adição de microssílica ao refratário $\mathrm{Al}_{2} \mathrm{O}_{3}-\mathrm{ZrO}_{2}$ resulta em uma melhoria significativa de suas propriedades tecnológicas, pois a sílica tem menor ponto de fusão em relação à alumina, podendo, com isso, haver formação de fase vítrea. Tal fase tende melhorar a densificação através de sinterização em fase líquida, bem como conferir aumento da resistência mecânica desses materiais $[5,6]$

Mulita é uma fase cristalina comumente utilizada em cerâmicas refratárias por apresentar excelentes propriedades tais como: elevada refratariedade e alto módulo de ruptura, boa resistência ao choque térmico, a erosão e ao ataque químico. A reação de mulitização ocorre pelo mecanismo de nucleação e crescimento. Com o aumento da temperatura, inicia-se a interdifusão dos íons nas interfaces entre as partículas de alumina e sílica. Majoritariamente os íons provenientes da alumina se difundem para o interior das partículas de sílica, formando um líquido silicoaluminoso [7-9]. Aumentando-se ainda mais a temperatura, a difusão dos íons prossegue e o líquido se enriquece gradativamente em íons alumínio até as quantidades dos íons silício e alumínio atingirem a proporção estequiométrica da fase. Inicia-se assim a nucleação da mulita, seguida pelo seu crescimento que ocorre por difusão e precipitação.

Dentre os refratários especiais que têm sido desenvolvidos para atender ás solicitações severas na siderurgia, destacam-se os refratários de alta alumina ligado a carbono com adição de agregado eletrofundido de mulita-zircônia utilizados para a confecção das placas de válvula gaveta [10]. O intuito de se utilizar o agregado 
mulita-zircônia substituindo uma parte da fração grossa da alumina é o de promover uma maior interação da trinca com a microestrutura do material, uma vez que a adição de partículas finas de zircônia não surtem o efeito de tenacificação por microtrincamento em refratários, pois esses materiais já possuem uma microestrutura altamente microtrincada ou porosa. O agregado de alumina eletrofundida também age da mesma forma, pois se trata de uma característica física do agregado.

Deste modo, neste trabalho adicionou-se teores variados de microssilica ao refratário do sistema $\mathrm{Al}_{2} \mathrm{O}_{3}-\mathrm{ZrO}_{2}$, no intuito de melhorar propriedades mecânicas, tecnológicas, bem como a resistência ao choque térmico. Além de microssílica, inseriu-se também agregado de alumina eletrofundida, com objetivo de aumentar a resistência à propagação de trincas, pois sabe-se que a inserção de uma segunda fase ao material parece ser o método mais eficiente. [11]

\section{MATERIAIS E MÉTODOS}

As matérias-primas empregadas foram: alumina calcinada com pureza (APC-G, Alcoa, Brasil), zircônia monoclínica, mircrossílica e agregado de alumina eletrofundida. Todas com grau de pureza superior a $99 \%$. Os pós foram moídos em recipiente de polietileno no moinho de jarros por $3 \mathrm{~h}$ em suspensão de álcool isopropílico, para melhor homogeneização, utilizando-se $1,0 \%$ do ligante PVB (Butvar B-98) e 0,5\% do lubrificante ácido oléico.

Tabela 1. Formulações dos corpos de prova utilizadas

\begin{tabular}{lcccc}
\hline \multicolumn{1}{c}{ ID } & $\mathrm{Al}_{2} \mathrm{O}_{3}(\%)$ & $\mathrm{ZrO}_{2}(\%)$ & $\mathrm{SiO}_{2}(\%)$ & Agregado(\%) \\
\hline F0-SM & 75 & 5 & - & 20 \\
F1-M & 60 & 5 & 15 & 20 \\
F2-M & 50 & 5 & 25 & 20 \\
F3-M & 40 & 5 & 35 & 20 \\
F4-M & 25 & 5 & 50 & 20 \\
\hline
\end{tabular}

As composições foram secas, peneiradas em peneiras de abertura de 100 mesh, proporcionadas, e em seguida conformados em amostras de $60 \times 20 \times 6 \mathrm{~mm}$ por prensagem uniaxial a 7 tn de tensão. Foram confeccionados 5 corpos de prova para cada composição e os mesmos foram secos em estufa por $24 \mathrm{~h}$ a $105^{\circ} \mathrm{C}$. Posteriormente seguiu-se com calcinação a $300^{\circ} \mathrm{C}$ por $2 \mathrm{~h}$, e sinterização a $1600^{\circ} \mathrm{C}$ por $2 \mathrm{~h}$ com taxa de aquecimento de $10^{\circ} \mathrm{C} / \mathrm{min}$. As amostras obtidas foram caracterizadas por medidas de densidade aparente, retração linear de queima, porosidade aparente e absorção de água utilizando-se o método de Arquimedes. Foi feito ensaio de choque térmico à $1000^{\circ} \mathrm{C}$, afim de verificar a resistência com a adição da microssílica. A resistência mecânica foi medida por ensaio de Módulo de Ruptura à Flexão (MoR), realizado no laboratório de metalografia e tratamento térmico da Universidade Federal do Pará, campus Tucuruí. Amostras de cada composição foram selecionadas para análise micrográfica por microscopia eletrônica 
de varredura (MEV). Também foram colhidas amostras para realização de análise por difração de raios-X.

\section{RESULTADOS E DISCUSSÃO}

\subsection{Propriedades Tecnológicas}

Os resultados obtidos através do ensaio de Arquimedes estão expressos na Tabela 2. Estes demonstram as propriedades tecnológicas de Absorção de Água (AA), Porosidade Aparente (PA) e Densidade Aparente (DA) e retração linear de queima (RLQ). Os dados tabelados são médias obtidas após tratamento estatístico dos resultados individuais dos corpos de prova submetidos à sinterização nas diferentes temperaturas.

Tabela 2. Resultados obtidos após sinterização e propriedades tecnológicas

\begin{tabular}{ccccc}
\hline Teor de $\mathrm{SiO}_{2}$ & $\mathbf{A A}(\%)$ & $\mathbf{P A}(\%)$ & $\mathbf{D A}\left(\mathbf{g} / \mathbf{c m}^{3}\right)$ & $\mathbf{R L Q}(\%)$ \\
\hline $\mathbf{0 \% ( F 0 )}$ & 6,06 & 18,92 & 3,33 & 4,45 \\
$\mathbf{1 5 \% ( F 1 )}$ & 12,73 & 30,34 & 2,69 & 0,86 \\
$\mathbf{2 5 \% ( F 2 )}$ & 13,64 & 29,94 & 2,50 & 0,73 \\
$\mathbf{3 5 \% ( F 3 )}$ & 9,89 & 22,06 & 2,45 & 2,06 \\
$\mathbf{5 0} \%(\mathrm{~F} 4)$ & 0,65 & 1,68 & 2,61 & 12,53 \\
\hline
\end{tabular}

Em uma análise dos resultados obtidos, é necessária uma atenção especial para a formulação $\mathrm{F} 0$ e $\mathrm{F} 4$, essas formulações chamam a atenção devido uma diminuição significativa nos teores de absorção de água e de porosidade aparente, quando comparados os resultados das outras formulações. A formulação F1 que não possui adição de Microssilica, as fases predominantes deste tipo de refratário são Coríndon e Zircônia monoclínica, que quando sinterizados a $1600^{\circ} \mathrm{C}$ formam um compósito de alta densificação e elevada resistência à fratura, isso é atribuído devido a formação de microtrincamento das partículas na matriz e o mecanismo de reforço de partículas devido a Zircônia se depositar nos pontos triplos dos grãos. Já na formulação F4 temos uma grande formação de fase vítrea, onde essa fase vítrea durante a sinterização se tornou fase liquida o que acarretou em uma sinterização na presença de liquido, que torna a densificação do refratário ainda melhor, isso explica valores tão baixos de $A A$, além de que a PA é diretamente influenciada quando se tem presença de fase liquida na sinterização, onde que nestes casos a porosidade é reduzida drasticamente. Como nesta formulação houve uma maior quantidade de fase mulita formada, teve o aumento da interligação entre os grãos, tanto maiores quanto menores, o que ocasionou uma microestrutura mais coesa, de menor porosidade e densidades.

A incorporação de Microssilica na composição do refratário, F1 e F2 resultou em uma diminuição nas propriedades tecnológicas, isso pode ser explicado por uma competição entre as partículas de Zircônia e Partículas microssílica nos espaços vazios, como a formação de fase vítrea foi pouca há uma possibilidade das partículas não se arranjarem além que na presença de pouca ou nenhuma formação de fase vítrea se têm uma microestrutura bimodal, onde que as partículas se concentram em determinados pontos da microestrutura. 
Cabe destacar o que diz Magliano [13], sobre a possível influência de impurezas para a formação de mulita na sinterização. Segundo o autor, a presença de impurezas, de um modo geral, reduz a temperatura de formação do líquido silicoso metaestável e diminui sua viscosidade favorecendo a mulitização. A quantidade e o tipo de impurezas influenciam no formato dos cristais de mulita obtidos. Então, por essa afirmação, não pode-se descartar a hipótese de que as impurezas oriundas dos agregados de alumina e alumina eletrofundida tenham colaborado para a mulitização com baixas proporções de sílica e baixa temperatura, isso pode explicar as anomalias que ocorreram em F1 e F2.

Com a variação das formulações percebe-se que as propriedades tecnológicas melhoraram gradativamente para praticamente todos os casos. F3 à $1600{ }^{\circ} \mathrm{C}$ obteve uma porosidade de $22,06 \%$, um resultado significativo se levarmos em consideração o tipo de aplicação do refratário. Deve-se ressaltar que, os poros encontrados na microestrutura são poros considerados pequenos e bem distribuídos na microestrutura o que melhora ainda mais as propriedades térmicas destes além de estes se enquadrarem no tipo de refratário de baixa porosidade que possuem melhor resistência ao ataque químico, à corrosão, à penetração de gases, escórias, metal líquido e erosão, levando este tipo de refratário um forte candidato para revestimento de panelas siderúrgicas usadas na Aciária

\subsection{Resistência ao Choque Térmico e a Flexão}

No que diz respeito ao ensaio de choque térmico percebeu-se que a adição de microssílica desde pequenas quantidades foi benéfica, de 15 corpos de provas ensaiados, apenas 1 corpo de prova da formulação 0, formulação esta sem microssílica, apresentou falha catastrófica, comprovando assim o aumento da resistência ao choque térmico com a formação da fase mulita.

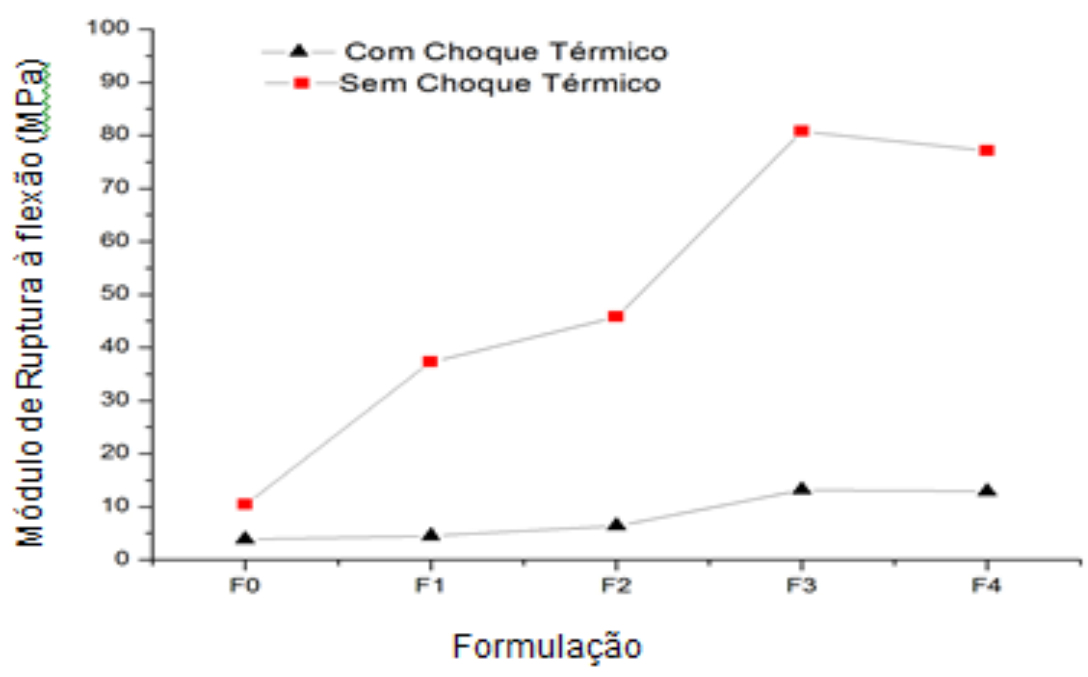

Figura 1. Resultados para MoR em 3 pontos com e sem choque térmico.

A figura 01 demonstra a comparação entre formulações com e sem o choque térmico em relação à resistência mecânica, a partir dos ensaios de flexão em 3 pontos. 
Analisando a figura acima pode-se inferir que a mesma está condizente com a literatura, pois pode-se ver uma diminuição do módulo de ruptura nos corpos de prova após o choque térmico, demonstrando contudo um aumento na resistência com o aumento do teor de microssílica. Tal aumento é explicado pelo fato de que há a formação da fase mulita com a adição de microssílica, tal fase é responsável pelo aumento da resistência mecânica, bem como da resistência ao choque térmico.

Nota-se na figura 02 o aumento da resistência mecânica com a adição de microssílica, onde para a formulação 0 (Figura 2.b) que passou pelo choque térmico, se tinha um módulo de ruptura de 3,83, já para a formulação 3 (Figura 2.a), que foi a que apresentou um maior módulo de ruptura, teve-se uma resistência de cerca de 13,15, ou seja, se teve um aumento de mais de 3 vezes de resistência mecânica. Tal fato confirma a importância da microssílica, pois a mesma promove uma maior coesão entre as partículas de alumina e possibilita o ganho na resistência mecânica mesmo com uma porosidade relativamente alta.

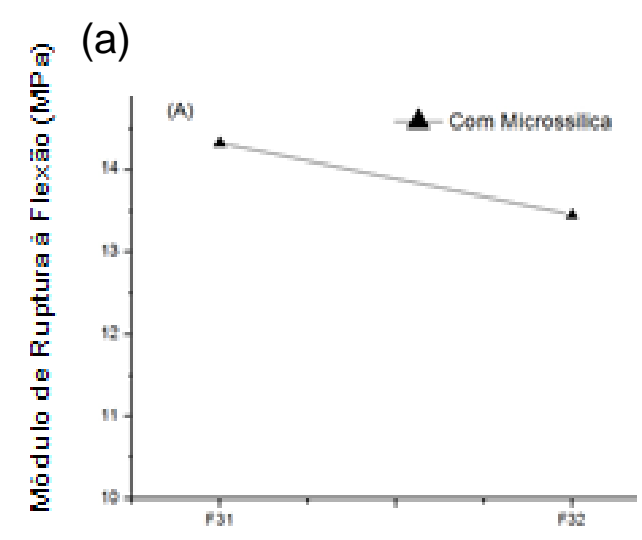

Teor de $\mathrm{SiO}_{2}(\%)$

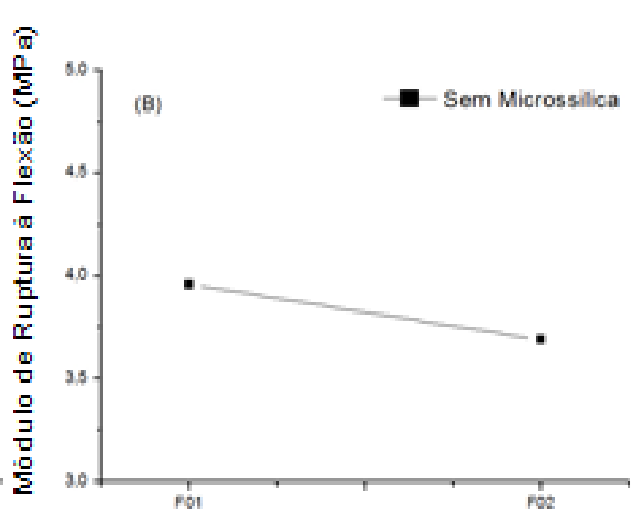

Teor de $\mathrm{SiO}_{2}(\%)$

(b)

Figura 2. Resultados para MoR em 3 pontos com e sem adição de microssílica.

\subsection{Microscopia Eletrônica de Varredura (MEV)}



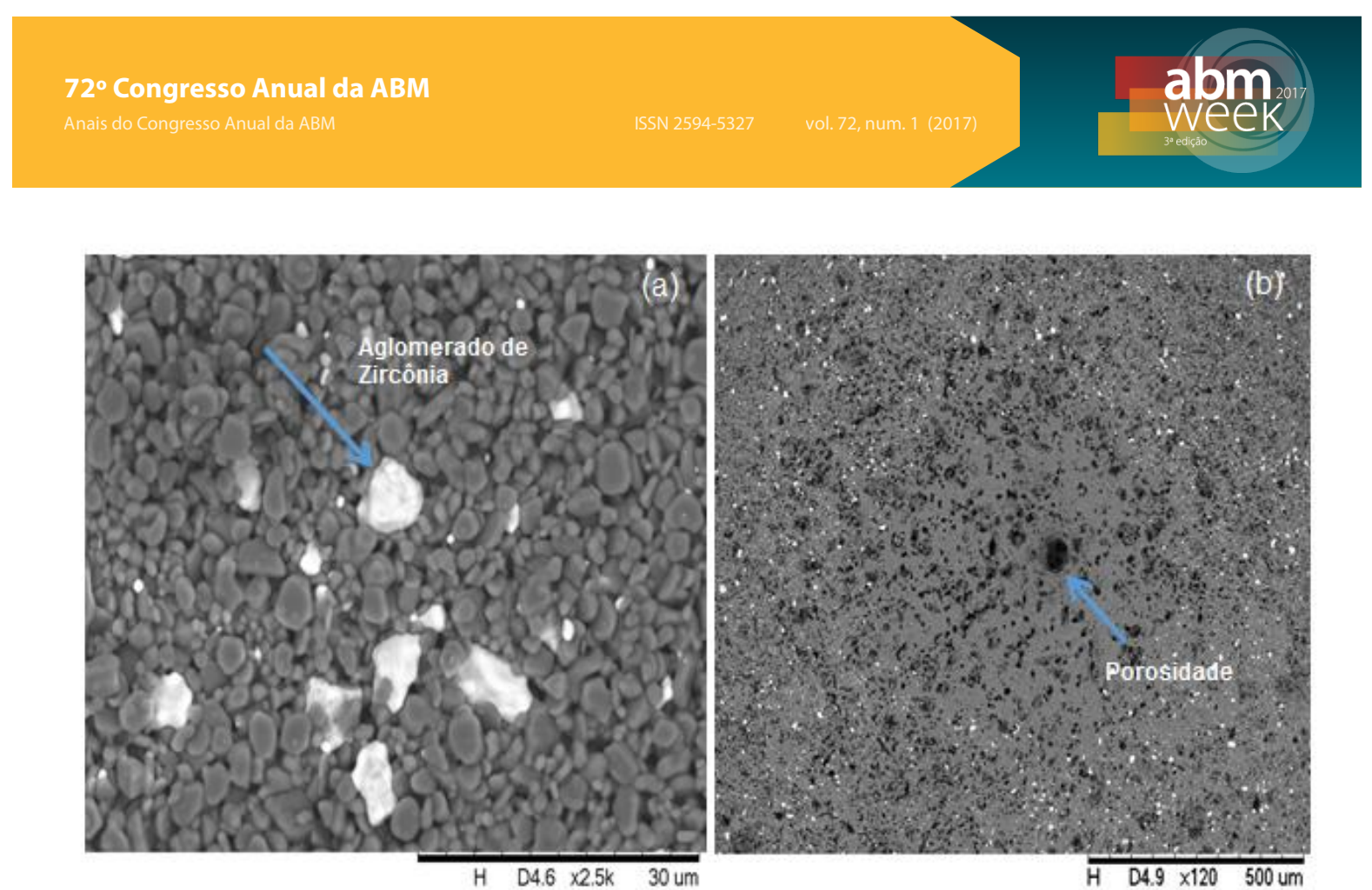

IGE-UNIFESSPA

IGE-UNIFESSPA

Figura 3. (a) Visão geral da superfície, com empacotamento das partículas e aglomerado formado em F0; (b) Porosidade na matriz.

A análise da figura 03 , oriunda do microscópio eletrônico de varredura (MEV) da amostra sem microssílica, revela uma microestrutura sem contornos de grãos de fácil identificação, mostrando-se como uma superfície de granulometria grosseira (A). Na figura B pode-se ver claramente zircônia dispersas na estrutura, o que significa que não houve formação de solução sólida entre os componentes, na figura 04 pode-se observar pontos de segregação da mesma na formulação.

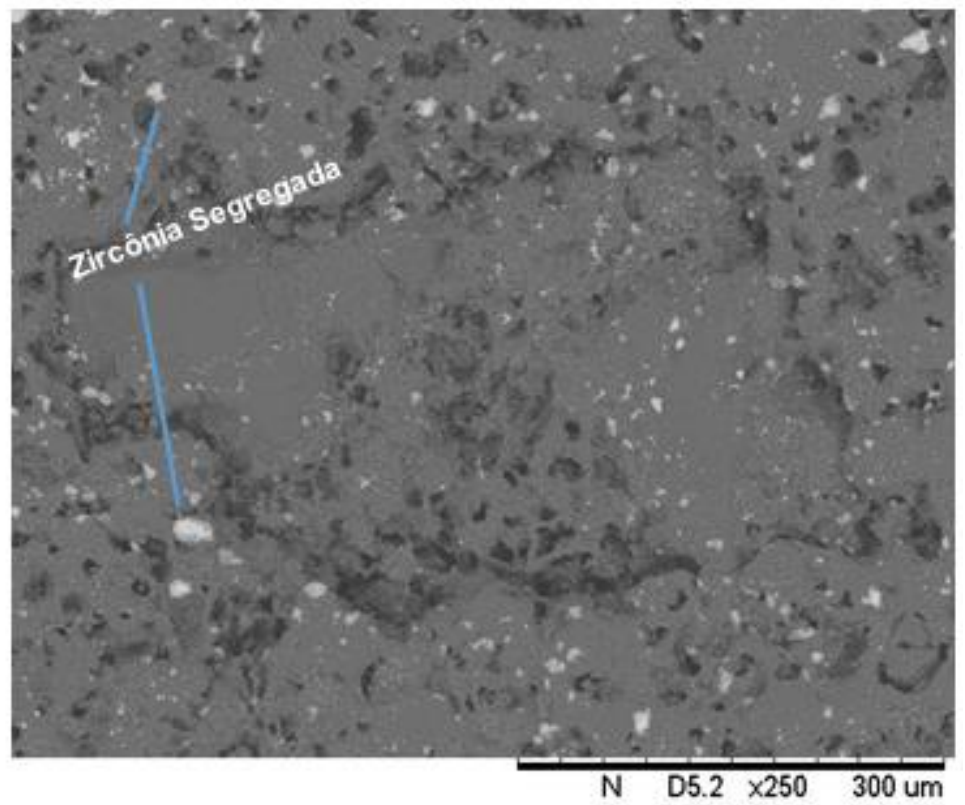

IGE-UNIFESSPA

Figura 4. Pontos de Segregação de zircônia na F1. 


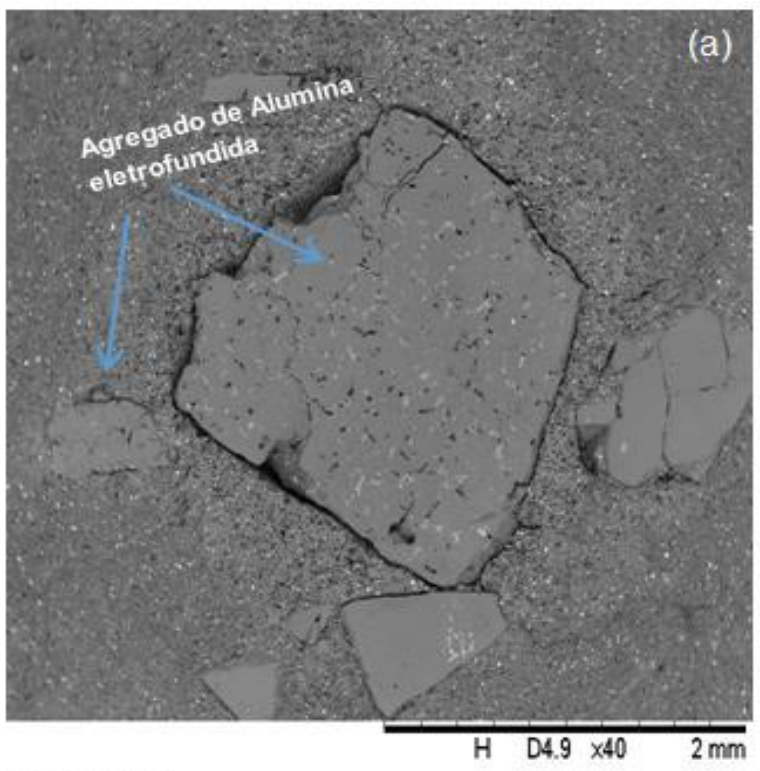

IGE-UNIFESSPA

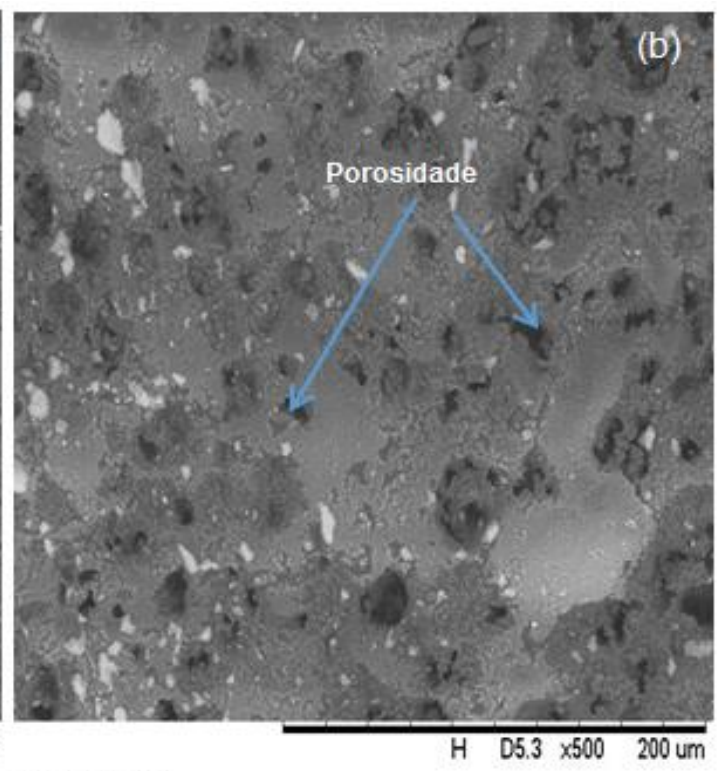

IGE-UNIFESSPA

Figura 5. (a) Agregado de Alumina Eletrofundida na F1; (b)Porosidade na matriz.

$\mathrm{Na}$ figura 5 nota-se o agregado de alumina eletrofundida, onde percebe-se claramente a falta de interação do mesmo com a matriz, onde esta falta de interação pode ser oriunda da competição entre fase mulita presente na matriz e alumina presente no agregado. Percebe-se também vários pontos de segregação de zircônia, inclusive no agregado (A). Na figura B é notório uma microestrutura com porosidade, esta pode ter sido proveniente de formação de aglomerados durante 0 processamento, bem como uma secagem não adequada, o que pode ter ocasionado uma sinterização não eficaz.

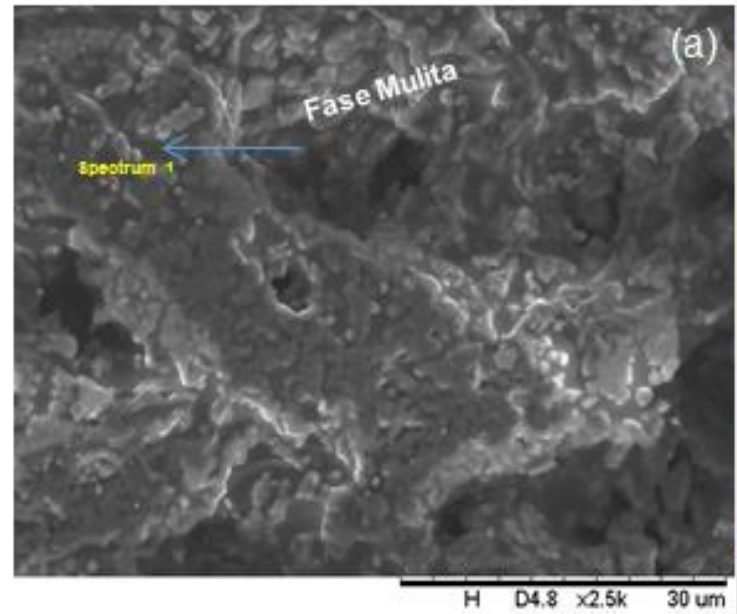

IGE-UNIFESSPA

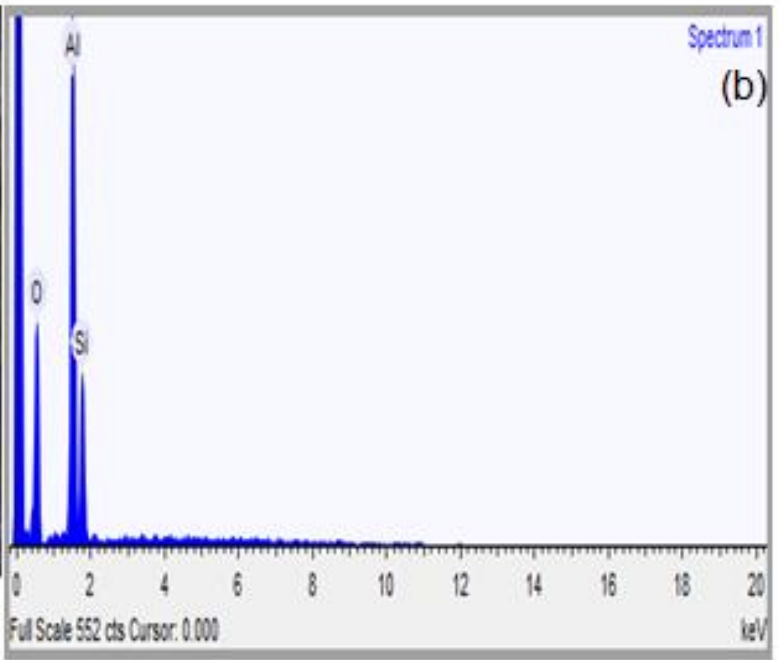

(b)

tolv

Figura 6. (a) Fase vítrea formada a partir da microssílica em F3; (b) Resultado da análise por EDS para F3.

Acima tem-se a formação da fase mulita (a), nota-se que os grãos da microestrutura estão envolvidos por essa fase, percebe-se também uma dispersão 
homogênea da Zircônia além da quantidade pequena de poros. Como já falado, a formação de fase vítrea aumenta o desempenho sobremaneira dos corpos refratários. A análise por energia dispersiva (EDS) nessa região corroborou com os resultados obtidos, apontando a presença de Si no ponto averiguado, conforme os picos da Figura 6.b.

\subsection{Difração de Raios X}

Os difratogramas resultantes das análises em raios $\mathrm{x}$ demonstraram a presença das fases de interesse para o presente trabalho, principalmente da mulita. A figura 7 apresenta a composição dos difratogramas das formulações 0, 1, 2,3 e 4 .

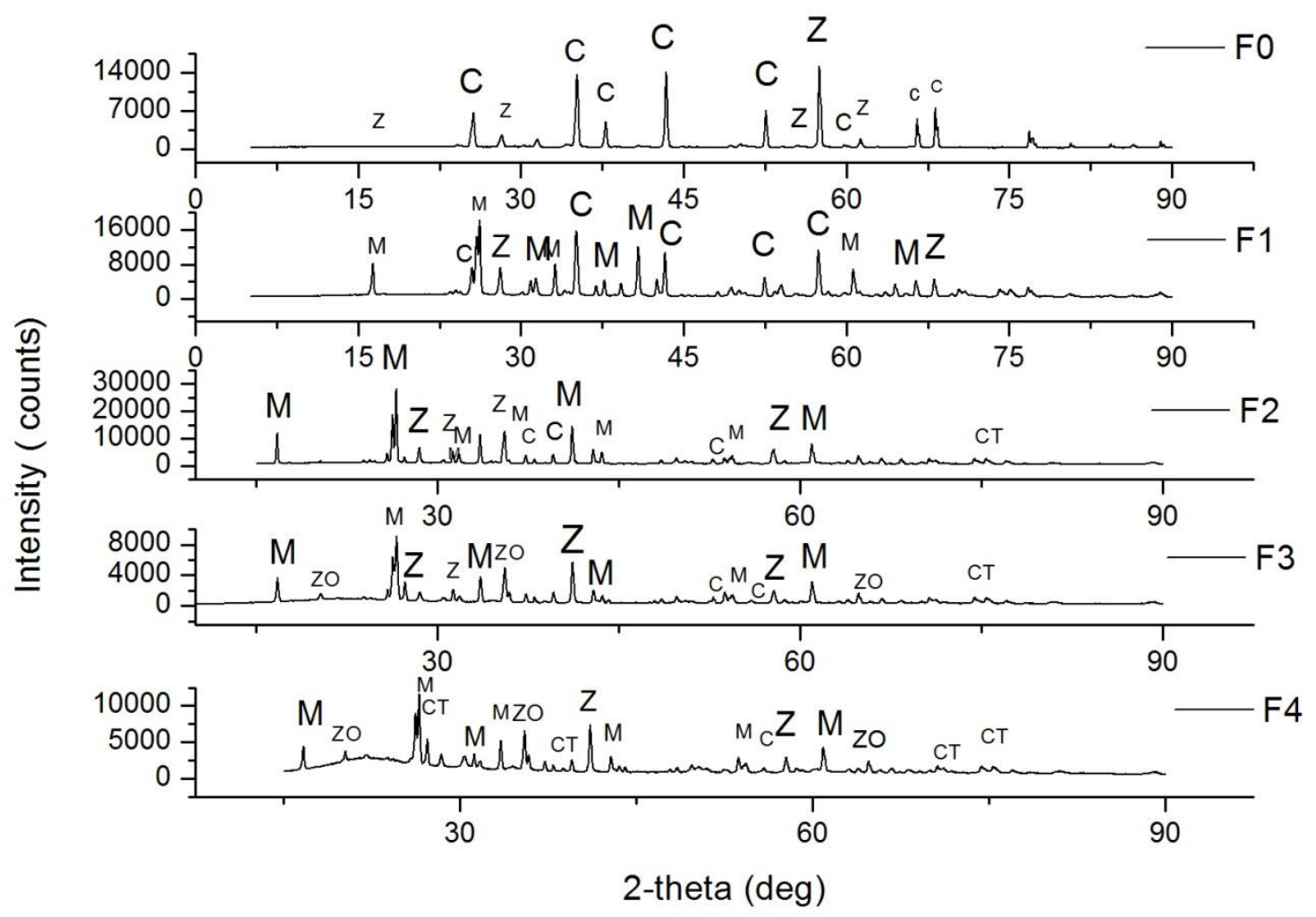

Figura 7. Difratogramas a $1600^{\circ} \mathrm{C}$ para $\mathrm{F} 1$, F2, F3 e F4. C refere-se a alumina ( coríndon), Z à zircônia, M à mulita, CT à cristobalita e ZO ao zircão.

Como era de se prever houve a formação de alumina, na forma de coríndon, e zircônia, para a formulação 0 . A partir da formulação 1 nota-se a incidência de picos da fase mulita, percebe-se que com o aumento no teor de microssílica houve pouca modificação nestes picos.

A partir de F1 percebe-se a predominância de picos de mulita, sendo que em F3 observa-se o aparecimento de picos de zircão, mineral onde geralmente se obtém a zircônia. Estes picos podem ter acarretado a não identificação de alguns picos nas formulações 3 e 4 . Observa-se também nestas formulações 0 aparecimento de cristobalita, polimorfo metaestável da sílica, este é resultante da alta temperatura de sinterização. 


\section{CONCLUSÃO}

Em suma pode-se inferir que a análise dos refratários estudados revelou microestruturas compostas de a-alumina, mulita e cristobalita, todas de alta refratariedade. Também destaca-se a presença da zircônia monoclínica, responsável pelas microtrincas que podem ser apontadas como o principal mecanismo de tenacificação. Observou-se que a concentração de mulita foi mais apreciável nas formulações com maior teor de microssílica. A formação da mulita nos refratários deste trabalho foi determinante para bons resultados quanto à resistência mecânica e resistência ao choque térmico, devido muito a sua baixa condutividade térmica e baixo coeficiente de expansão térmica. Vale ressaltar que a presença do agregado de alumina foi prejudicial ao refratário, devido a sua granulometria grosseira. Observou-se que o mesmo apresentou uma microestrutura com falta de ligação entre matriz fina e os grandes grãos do agregado. $O$ fato do mesmo ser de alumina pode ter gerado uma competição entre a matriz, o que ocasiona a formação de trincas, acarretando assim uma diminuição nas propriedades mecânicas do mesmo.

\section{Agradecimentos}

O presente trabalho foi realizado com o apoio da Universidade Federal do Sul e Sudeste do Pará e PIBIC/FAPESPA.

\section{REFERÊNCIAS}

[1] MELO, F.C.L. Conjugados cerâmicos obtidos a partir da sinterização reativa entre zirconita e alumina. 1989, 82p. Dissertação (Mestrado em Engenharia de Materiais) - Universidade Federal de São Carlos- UFSCar, São Carlos.

[2] SAKO, E.Y.; PANDOLFELLI, V.C. A relação entre a corrosão e a microestrutura: a chave para 0 desenvolvimento de concretos refratários espinelizados de alto desempenho. Cerâmica, v. 60, p. 127-143, 2014.

[3] LEE, W.E. et al. Castable refractory concretes. International Materials Reviews, v. 46, n. 3, p. 145-167, 2001.

[4] GONÇALVES, L.R.G. Erosimetria a quente: equipamento, adequações e correlações dos valores obtidos com as propriedades de concretos refratários. Dissertação (Mestrado) - Centro de Ciências Exatas e Tecnológicas. Universidade Federal de São Carlos - UFSCar, São Carlos 2011. 124p.

[5] FERRARI, C.R.; RODRIGUES, J.A. Refratários de alumina contendo agregado de mulita-zircônia: aspectos microestruturais. Cerâmica, v. 46, n. 298, 2000.

[6] MARINHO, A.R.O.; RABELO, A.A. Avaliação das propriedades tecnológicas de refratários dos sistemas sistemas alumina-zircônia e alumina-zircôniasílica. 21ํㅡㄹ Congresso Brasileiro de Engenharia e Ciência dos Materiais, Cuiabá, 2014.

[7] S. H. Risbud, J. A. Pask, SiO2-Al2O3, Metastable Phase Equilibrium Diagram without Mullite, J. Mater. Sci. 13 (1978) 2449-2454.

[8] Y. Sung, Determination of Interdifusion Coefficient of Mullite Formation Reaction via Kinetics Analysis, J. Mater. Sci. Lett. 20 (2001) 1433-1434.

[9] M. Schneider, K. Okada, J. A. Pask, Mullite and Mullite Ceramics, John Wiley \& Sons, Nova York, EUA (1994) 83-145. 
[10] Z. Xiangchong, S. Gengchen and L. Xinyu, "High Temperature Properties of Carbon-Bonded Corundum-Mullite-Zirconia Materials", In: UNICENTER, 1, 1989, USA. Proceedings. USA: American Ceramic Society, (1989)1803-1813.

[11] FERREIRA, L.L.H.C. Desenvolvimento de agregados eletrofundidos para utilização em refratários para a zona de queima de fornos de cimento. Tese (Doutorado) - Instituto de Pesquisas Energéticas e Nucleares, IPEN/USP, São Paulo, 2006. 192p.

[12] RODRIGUES J. A.PERET C. M.,PANDOLFELLI V. C. Avaliação dos parâmetros de choque térmico em alta temperatura de refratários. In: CONGRESSO BRASILEIRO DE CERÂMICA, 44, São Pedro, 2000. Anais. São Pedro-SP: Associação Brasileira de Cerâmica, 2000. p.1-3.

[13] MAGLIANO, M.V.M.; PANDOLFELLI, V. C. Mulitização em refratários utilizando diferentes fontes precursoras - revisão. Cerâmica, v. 56, p. 368-375, 2010. 